\title{
End-tidal carbon dioxide monitoring using a naso-buccal sensor is not appropriate to monitor capnia during non-invasive ventilation
}

\author{
Lise Piquilloud $^{1 *}$, David Thevoz ${ }^{1,2}$, Philippe Jolliet ${ }^{1}$ and Jean-Pierre Revelly ${ }^{1}$
}

\begin{abstract}
Background: In acute respiratory failure, arterial blood gas analysis (ABG) is used to diagnose hypercapnia. Once non-invasive ventilation (NIV) is initiated, ABG should at least be repeated within $1 \mathrm{~h}$ to assess $\mathrm{PaCO}_{2}$ response to treatment in order to help detect NIV failure. The main aim of this study was to assess whether measuring end-tidal $\mathrm{CO}_{2}\left(\mathrm{EtCO}_{2}\right)$ with a dedicated naso-buccal sensor during NIV could predict $\mathrm{PaCO}_{2}$ variation and/or $\mathrm{PaCO}_{2}$ absolute values. The additional aim was to assess whether active or passive prolonged expiratory maneuvers could improve the agreement between expiratory $\mathrm{CO}_{2}$ and $\mathrm{PaCO}_{2}$.

Methods: This is a prospective study in adult patients suffering from acute hypercapnic respiratory failure $\left(\mathrm{PaCO}_{2} \geq\right.$ $45 \mathrm{mmHg}$ ) treated with NIV. EtCO $\mathrm{En}_{2}$ and expiratory $\mathrm{CO}_{2}$ values during active and passive expiratory maneuvers were measured using a dedicated naso-buccal sensor and compared to concomitant $\mathrm{PaCO}_{2}$ values. The agreement between two consecutive values of $\mathrm{EtCO}_{2}$ (delta $\mathrm{EtCO}_{2}$ ) and two consecutive values of $\mathrm{PaCO}_{2}\left(\right.$ delta $\mathrm{PaCO}_{2}$ ) and between $\mathrm{PaCO}_{2}$ and concomitant expiratory $\mathrm{CO}_{2}$ values was assessed using the Bland and Altman method adjusted for the effects of repeated measurements.
\end{abstract}

Results: Fifty-four datasets from a population of 11 patients (8 COPD and 3 non-COPD patients), were included in the analysis. $\mathrm{PaCO}_{2}$ values ranged from 39 to $80 \mathrm{mmHg}$, and $\mathrm{EtCO}_{2}$ from 12 to $68 \mathrm{mmHg}$. In the observed agreement between delta $\mathrm{EtCO}_{2}$ and deltaPaCO , bias was $-0.3 \mathrm{mmHg}$, and limits of agreement were -17.8 and $17.2 \mathrm{mmHg}$. In agreement between $\mathrm{PaCO}_{2}$ and $\mathrm{EtCO}_{2}$, bias was $14.7 \mathrm{mmHg}$, and limits of agreement were -6.6 and $36.1 \mathrm{mmHg}$. Adding active and passive expiration maneuvers did not improve $\mathrm{PaCO}_{2}$ prediction.

Conclusions: During NIV delivered for acute hypercapnic respiratory failure, measuring $\mathrm{EtCO}_{2}$ using a dedicating naso-buccal sensor was inaccurate to predict both $\mathrm{PaCO}_{2}$ and $\mathrm{PaCO}_{2}$ variations over time. Active and passive expiration maneuvers did not improve $\mathrm{PaCO}_{2}$ prediction.

Trial registration: ClinicalTrials.gov: NCT01489150.

Keywords: Respiratory monitoring; Non-invasive ventilation; End-tidal $\mathrm{CO}_{2}$; Hypercapnic respiratory failure

\section{Background}

Non-invasive ventilation (NIV) is widely used [1] in emergency rooms, in intensive and intermediate care units, and in recovery rooms to treat de novo and, even if it is more debatable [2,3], postextubation hypercapnic respiratory failure. Arterial blood gas analysis (ABG) is usually performed to diagnose hypercapnia and should at least be

\footnotetext{
*Correspondence: lise.piquilloud@chuv.ch

${ }^{1}$ Adult Intensive Care and Burn Unit, University Hospital of Lausanne, Lausanne, Switzerland

Full list of author information is available at the end of the article
}

repeated within $1 \mathrm{~h}$ after NIV initiation to assess $\mathrm{PaCO}_{2}$ response to treatment [1]. However, as follow-up ABG requires a new arterial puncture in patients not previously equipped with an arterial line, this exam is often postponed with the risk of delaying NIV failure diagnosis and intubation, a condition previously associated with poor outcome [4]. Only a reliable non-invasive monitoring of the course of $\mathrm{PaCO}_{2}$ during NIV could avoid such a delay and help optimizing ventilator settings. End-tidal $\mathrm{CO}_{2}\left(\mathrm{EtCO}_{2}\right)$ monitoring is easy to perform and widely used during anesthesia to assess the adequacy of delivered 
minute ventilation without performing repetitive ABG $[5,6]$. Using capnometry to monitor capnia in non-intubated patients during NIV is much more challenging. Indeed, during NIV, gas leak occurs in the respiratory 'circuit' and conceivably, in this situation, only gas sampling directly at the level of the patient's airways can reflect true expiratory gas.

As new specialized naso-buccal EtCO ${ }_{2}$ sensors have recently been developed to collect expired gas directly at the airway opening, there is now an opportunity to use capnometry to monitor capnia during NIV. The main aim of this study was to assess the ability of a dedicated $\mathrm{EtCO}_{2}$ naso-buccal sensor to predict $\mathrm{PaCO}_{2}$ variations and/or $\mathrm{PaCO}_{2}$ absolute values in hypercapnic patients during NIV. The second aim of the study was to assess whether active or passive prolonged expiratory maneuvers could improve the agreement between expiratory $\mathrm{CO}_{2}$ and $\mathrm{PaCO}_{2}$.

\section{Methods}

A prospective pilot study was conducted in our medicosurgical ICU in Lausanne, Switzerland. The hospital ethics committee (Human Research Ethics Committee of Lausanne, Switzerland) approved the study protocol, and written informed consent was obtained before inclusion in the study. In the absence of published data reporting the use of a naso-buccal sensor to measure $\mathrm{EtCO}_{2}$ in acutely ill patients undergoing NIV, no power computation could be performed.

\section{Patients}

Non-intubated patients suffering from hypercapnic $\left(\mathrm{PaCO}_{2} \geq 45 \mathrm{mmHg}\right)$ acute respiratory failure, hospitalized in the ICU, equipped with an arterial line and requiring NIV could be included in the study if they had no major hemodynamic instability, no facial lesion preventing the use of the naso-buccal sensor, and no cognitive disability or psychiatric disease liable to interfere with NIV. To note, as only patients admitted in the ICU and already equipped with an arterial line could be included in the study, the NIV treatment monitored in the study was usually not the first NIV treatment delivered to the patients.

\section{Study protocol and measurements}

Upon inclusion, the patient was equipped with the Smart CapnoLine $^{\bullet}$ naso-buccal sensor (Figure 1 ) designed to collect expiratory gas immediately at the airway opening both at the nose and mouth levels connected to the Capnostream 20 monitor $^{\circ}$ (Oridion Medical Ltd, Jerusalem, Israël). To perform the measurement, a sample of gas is transmitted from the patient to a micro-cell of $15 \mu \mathrm{l}$ located in the monitor (sidestream capnography system). A sample of gas of $50 \mathrm{ml} / \mathrm{min}$ is needed for

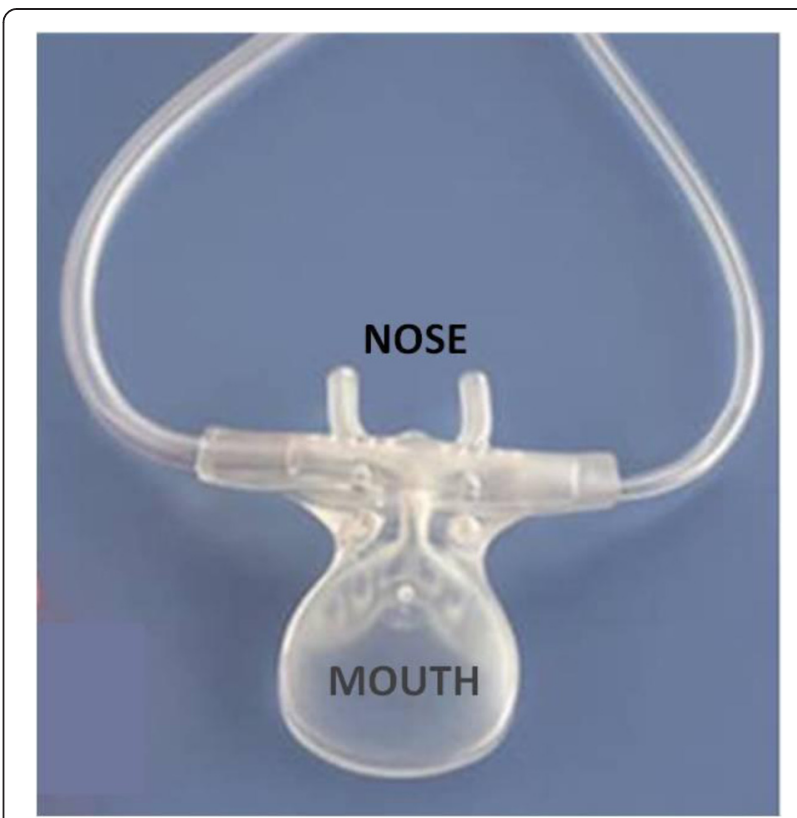

Figure 1 Naso-buccal sensor. Illustration of the naso-buccal sensor used in this study. This device is designed to collect expiratory gas immediately at the airway opening both at the nose and mouth levels.

the measurement. The measurement is performed by nondispersive infrared spectroscopy. For each respiratory cycle, the capnogram is displayed on the Capnostream 20 monitor. For each $\mathrm{EtCO}_{2}$ value recorded, the investigator checked the good quality of the capnogram displayed on the screen. The value of one respiratory cycle was recorded at each measurement time.

$\mathrm{ABG}$ and the corresponding $\mathrm{EtCO}_{2}$ value displayed by the monitor were recorded as baseline values. NIV treatment was then initiated using an hermetic naso-buccal mask (Vygon Large ${ }^{\circ}$, Ecouen, France) held in place using

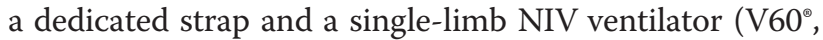
Respironics Philips, Amsterdam, Netherland). Calibrated intentional leakage to allow $\mathrm{CO}_{2}$ expiration was created in the respiratory circuit using the dedicated whisper swivel (Whisper swivel ${ }^{\circ}$, Respironics Philips, Amsterdam, Netherland). A flow sensor (Hamilton, Bonaduz, Switzerland) was placed between the patient and the whisper swivel and connected to an analog-to-digital converter (MP100, Biopac, Systems, Goleta, CA, USA) to continuously record the flow-time curve. The respiratory circuit with the additional flow sensor is schematized in Figure 2. ABG and $\mathrm{EtCO}_{2}$ values were recorded at $15,30,45$, and $60 \mathrm{~min}$ after the initiation of NIV. At times corresponding to each $\mathrm{PaCO}_{2}$ and $\mathrm{EtCO}_{2}$ measurements, insufflated volumes were measured offline for ten consecutive respiratory cycles (by integration of the inspiratory flow-time curve recorded by the flow sensor placed between the patient and the whisper swivel) and the mean value was computed. 


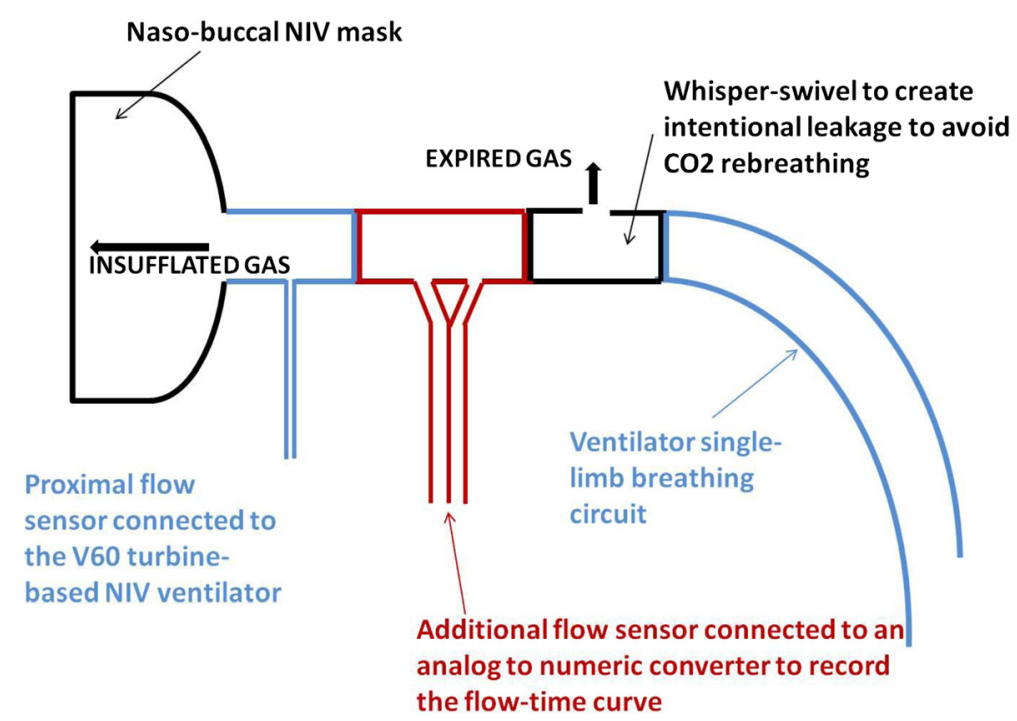

Figure 2 Respiratory circuit. Illustration of the respiratory circuit used in the study. From the patient to the ventilator, the circuit consists of an hermetic nasobuccal mask, the dedicated proximal flow sensor of the V60 ventilator, the additional flow sensor inserted to record insufflated and exuflated flow-time curves, the dedicated whisper swivel to create a calibrated intentional leak to avoid $\mathrm{CO}_{2}$ rebreathing, and the ventilator single-limb pipe.

Respiratory rate and delivered minute ventilation were also computed.

At 30 and 60 min after the beginning of NIV, the patient performed upon request a voluntary slow and maximal expiration. In brief, the patients were asked to slowly empty their lungs as much and for as long as possible. The expired $\mathrm{CO}_{2}$ value displayed at the end of this active expiration maneuver was recorded. A passive expiratory maneuver was then performed with the help of an experienced respiratory therapist (bilateral chest compression during slow expiration), and the corresponding expired $\mathrm{CO}_{2}$ value was recorded. The naso-buccal mask was not removed during the maximal expiratory maneuvers meaning that the patient expired through the nasobuccal sensor and the ventilator circuit and thus against the set PEEP. The backup safety respiratory frequency of the ventilator was set at 6 by minute to allow expiratory maneuvers of $10 \mathrm{~s}$.

\section{Calculations and statistics}

To assess $\mathrm{PaCO}_{2}$ variations, the differences between two consecutive $\mathrm{PaCO}_{2}\left(\right.$ delta $\mathrm{PaCO}_{2}$ ) values were computed for each patient between the initial value and the 15-min value, between the 15- and 30-min values, between the 30 - and 45-min values, and finally between the 45- and 60-min values. Delta $\mathrm{EtCO}_{2}$ were computed to assess $\mathrm{EtCO}_{2}$ variations according to the same procedure.

The $\mathrm{PaCO}_{2}-\mathrm{EtCO}_{2}$ gradient $\left(\mathrm{Pa}_{-\mathrm{E}} \cdot \mathrm{CO}_{2}\right)$ was computed for each patient with the pair of values recorded at the beginning of the NIV session and at 15, 30, 45 and $60 \mathrm{~min}$ after the initiation of NIV. The number of
$\mathrm{Pa}_{\mathrm{E}}, \mathrm{CO}_{2}$ values of more than $\pm 10 \mathrm{mmHg}$ was reported. The ratio of this number over the total number of measurements represents the proportion of clinically unacceptable $\mathrm{EtCO}_{2}$ values. The treshold of $10 \mathrm{mmHg}$ to consider $\mathrm{Pa}_{-\mathrm{E}}, \mathrm{CO}_{2}$ as clinically acceptable or not was an arbitrary choice.

All statistical analyses were performed using MedCalc Statistical Software version 12.7.2 (MedCalc Software, Ostend, Belgium). Considering the small number of included patients, non-normal distribution of the results was assumed. All results are given as median [25th and 75th percentile].

The agreement between delta $\mathrm{PaCO}_{2}$ and delta $\mathrm{EtCO}_{2}$ was assessed by the Bland and Altman method adjusted for the effect of repeated measurements. The differences between each deltaPaCO${ }_{2}$ and deltaEtCO values were also computed. The percentage of differences higher than $5 \mathrm{mmHg}$ was reported as they were arbitrarily considered as clinically unacceptable values.

Agreement between $\mathrm{PaCO}_{2}$ and $\mathrm{EtCO}_{2}$ absolute values was assessed using the Bland and Altman method adjusted for the effects of repeated measurements. Expiratory $\mathrm{CO}_{2}$ to $\mathrm{PaCO}_{2}$ agreement for values obtained after active and passive complete expirations was also computed with the Bland and Altman method adjusted for the effects of repeated measurements. The gradient between expiratory $\mathrm{CO}_{2}$ and $\mathrm{PaCO}_{2}$ was computed with the values obtained after active and passive complete expirations respectively. Clinically unacceptable values were arbitrarily defined as values above $10 \mathrm{mmHg}$. The proportions of clinically unacceptable gradients recorded were compared 
between normal expiration, active complete expiration, and passive complete expiration by chi-square test. $p<$ 0.05 was considered as statistically significant.

\section{Results}

The whole 45-min protocol could be applied to ten patients. In one patient (patient number 4), the NIV treatment had to be interrupted after 45 min because of intolerance. In this patient, the second set of active and passive expiratory manoeuvers was performed after $45 \mathrm{~min}$ instead of $1 \mathrm{~h}$, immediately before stopping NIV. Overall, 54-paired data sets of $\mathrm{PaCO}_{2}$ and $\mathrm{EtCO}_{2}$ from 11 patients (seven men/four women) could be recorded and were included in the analysis. Patients' demographic and clinical data are given in Table 1. Among the 11 included patients, eight patients had chronic obstructive pulmonary disease (COPD) of various severity (Table 1). Median age was 68 [62 and 77] years old and median SAPS II score was 43 [34 and 44]. Initial blood gas analysis, respiratory rate, inspired fraction of oxygen $\left(\mathrm{FIO}_{2}\right), \mathrm{PaO}_{2} / \mathrm{FIO}_{2}$ ratio, and initial ventilator settings during NIV are mentioned in Table 2.

During the study period, $\mathrm{PaCO}_{2}$ ranged from 39 to $80 \mathrm{mmHg}$, and $\mathrm{EtCO}_{2}$ from 12 to $68 \mathrm{mmHg}$. At the time of the measurements, delivered inspiratory volume was 724 [597-896] $\mathrm{ml}$ and delivered minute ventilation was $18.6[14.0-22.7] \mathrm{l} / \mathrm{min}$. When assessing the agreement between $\mathrm{EtCO}_{2}$ and $\mathrm{PaCO}_{2}$ gradients between two consecutive measurements, 43 paired data sets could be analyzed. The bias was $-0.3 \mathrm{mmHg}$ and the limits of agreement were -17.8 and $+17.2 \mathrm{mmHg}$. The Bland and Altman graphic representation is displayed in Figure 3.
Sixteen of 43 differences (37\%) between delta $\mathrm{PaCO}_{2}$ and delta $\mathrm{EtCO}_{2}$ were higher than $5 \mathrm{mmHg}$.

When assessing agreement between $\mathrm{PaCO}_{2}$ and $\mathrm{EtCO}_{2}$ absolute values, bias was $14.7 \mathrm{mmHg}$ and the limits of agreement were -6.6 and $36.1 \mathrm{mmHg}$ (Figure 4). The Bland and Altman graphic representation is displayed in Figure 4 both for COPD patients and non-COPD patients. $\mathrm{Pa}_{-}{ }_{\mathrm{E}} \mathrm{CO}_{2}$ was 12.4 [8.6-20.2] $\mathrm{mmHg}$ in median but very high values were documented in some patients (maximal value of $42.7 \mathrm{mmHg}$ ) and non-physiologic slightly negative values were observed in one patient (Figure 5). The number of clinically unacceptable values for $\mathrm{Pa}_{-\mathrm{E}} \mathrm{CO}_{2}$ was $35 / 54$ (65\%).

When we compared agreements between $\mathrm{PaCO}_{2}$, concomitant $\mathrm{EtCO}_{2}$, and expired $\mathrm{CO}_{2}$ after active and passive expiration maneuvers, we had 22-paired data available for each comparison. The bias was respectively 15.7, 9.9, and $9.8 \mathrm{mmHg}$. Bland-Altmann plots for active and passive expiration maneuvers are displayed in Figure 6A,B respectively. The number of clinically unacceptable gradient values was not different between the three measurements (respectively, 13 (60\%), 9 (41\%), and $9(41 \%), p=0.37$ ).

\section{Discussion}

Our results show that, in patients suffering from hypercapnic acute respiratory failure, measuring $\mathrm{EtCO}_{2}$ by a dedicated naso-buccal sensor during NIV was inaccurate to predict either $\mathrm{PaCO}_{2}$ variation over time or the absolute $\mathrm{PaCO}_{2}$ value. Adding complete passive or active expiratory maneuvers to expiratory $\mathrm{CO}_{2}$ measurements did not significantly improve the reliability of $\mathrm{PaCO}_{2}$ prediction.

Table 1 Patient's characteristics and clinical information.

\begin{tabular}{|c|c|c|c|c|c|c|c|c|}
\hline $\begin{array}{l}\text { Patient } \\
\text { number }\end{array}$ & Sex & $\begin{array}{l}\text { Age } \\
\text { [years] }\end{array}$ & $\begin{array}{l}\mathrm{BMI} \\
{\left[\mathrm{kg} / \mathrm{m}^{2}\right]}\end{array}$ & $\begin{array}{l}\text { SAPS } 2 \\
\text { score }\end{array}$ & Cause of acute respiratory failure & $\begin{array}{l}\text { Respiratory } \\
\text { comorbidity }\end{array}$ & $\begin{array}{l}\text { FEV1 (\% of } \\
\text { predicted value) }\end{array}$ & $\begin{array}{l}\text { GOLD } \\
\text { classification }\end{array}$ \\
\hline 1 & $\mathrm{~F}$ & 52 & 25.3 & 24 & COPD exacerbation & COPD & 36 & III \\
\hline 2 & M & 80 & 22.9 & 43 & Chest trauma with multiple rib fractures & None & & \\
\hline 3 & M & 68 & 24.5 & 58 & Pneumonia & COPD & 43 & III \\
\hline 4 & M & 59 & 42.6 & 44 & Acute lung injury (bacterial peritonitis) & COPD & 57 & $\|$ \\
\hline 5 & M & 77 & 29.3 & 43 & Pneumonia & COPD & 32 & III \\
\hline 6 & M & 77 & 29.4 & 43 & Acute lung injury (pancreatitis) & None & & \\
\hline 7 & M & 63 & 29.4 & 31 & COPD exacerbation & COPD & 33 & III \\
\hline 8 & M & 77 & 26.1 & 36 & Acute lung injury (peritonitis) & None & & \\
\hline 9 & $\mathrm{~F}$ & 71 & 22.0 & 45 & COPD exacerbation & COPD & Not available & Not available \\
\hline 10 & $\mathrm{~F}$ & 61 & 17.2 & 42 & COPD exacerbation & COPD & 28 & IV \\
\hline 11 & $\mathrm{~F}$ & 62 & 21.5 & 32 & Central hypoventilation (analgesia-sedation) & COPD & 54 & $\|$ \\
\hline Median & & 68 & 25.3 & 43 & & & & \\
\hline Centile 25 & & 62 & 22.5 & 34 & & & & \\
\hline Centile 75 & & 77 & 29.4 & 44 & & & & \\
\hline
\end{tabular}

F, female; M, male; FEV1, forced expiratory volume in $1 \mathrm{~s}$; COPD, chronic obstructive pulmonary disease; BMI, body mass index. 
Table 2 Respiratory rate, blood gas analysis at inclusion, and main initial ventilator settings

\begin{tabular}{|c|c|c|c|c|c|c|c|c|c|c|}
\hline $\begin{array}{l}\text { Patient } \\
\text { number }\end{array}$ & $\begin{array}{l}\text { RR } \\
\text { [cycles/min] }\end{array}$ & $\mathrm{SaO}_{2}[\%]$ & $\mathrm{pH}$ & $\begin{array}{l}\mathrm{PaCO}_{2} \\
{[\mathrm{mmHg}]}\end{array}$ & $\begin{array}{l}\text { Bicarbonates } \\
\text { [mmol/L] }\end{array}$ & $\begin{array}{l}\mathrm{PaO}_{2} \\
{[\mathrm{mmHg}]}\end{array}$ & $\mathrm{FIO}_{2}$ & $\begin{array}{l}\mathrm{PaO}_{2} / \mathrm{FIO}_{2} \\
\text { ratio }[\mathrm{mmHg}]\end{array}$ & $\begin{array}{l}\text { Initial IPAP } \\
{\left[\mathrm{cmH}_{2} \mathrm{O}\right]}\end{array}$ & $\begin{array}{l}\text { Initial EPAP } \\
{\left[\mathrm{cmH}_{2} \mathrm{O}\right]}\end{array}$ \\
\hline 1 & 12 & 93 & 7.41 & 45 & 27.7 & 62 & 0.28 & 159 & 15 & 10 \\
\hline 2 & 17 & 92 & 7.38 & 52 & 29.6 & 64 & 0.35 & 148 & 12 & 7 \\
\hline 3 & 16 & 88 & 7.46 & 45 & 31.1 & 53 & 0.5 & 89 & 14 & 6 \\
\hline 4 & 41 & 91 & 7.41 & 55 & 34.7 & 58 & 0.35 & 158 & 12 & 7 \\
\hline 5 & 21 & 94 & 7.32 & 80 & 39.8 & 67 & 0.4 & 200 & 20 & 8 \\
\hline 6 & 30 & 99 & 7.41 & 55 & 34.0 & 112 & 0.4 & 138 & 12 & 7 \\
\hline 7 & 27 & 92 & 7.42 & 61 & 38.8 & 62 & 0.5 & 123 & 8 & 5 \\
\hline 8 & 29 & 91 & 7.40 & 50 & 30.7 & 61 & 0.5 & 101 & 11 & 6 \\
\hline 9 & 25 & 90 & 7.33 & 58 & 29.4 & 58 & 0.4 & 145 & 15 & 6 \\
\hline 10 & 28 & 95 & 7.37 & 58 & 32.5 & 75 & 0.35 & 165 & 12 & 6 \\
\hline 11 & 20 & 92 & 7.47 & 51 & 36.7 & 59 & 0.3 & 171 & 15 & 6 \\
\hline Median & 25 & 92. & 7.41 & 55.3 & 32.5 & 62 & 0.4 & 148 & 12 & 6 \\
\hline Centile 25 & 19 & 91 & 7.37 & 51 & 30.2 & 58 & 0.35 & 131 & 12 & 6 \\
\hline Cetile 75 & 29 & 93 & 7.42 & 58 & 35.7 & 65 & 0.45 & 162 & 15 & 7 \\
\hline
\end{tabular}

$\mathrm{RR}$, respiratory rate; $\mathrm{SaO}_{2}$, oxygen saturation in arterial blood; $\mathrm{PaCO}_{2}$, carbon dioxide partial pressure in arterial blood; $\mathrm{PaO}$, oxygen partial pressure in arterial blood gas; $\mathrm{PaO}_{2} / \mathrm{FIO}_{2}$, oxygen partial pressure in arterial blood gas over inspired fraction of oxygen ratio; IPAP, set inspiratory pressure; EPAP, set expiratory pressure.

Before discussing the results in more details, we must acknowledge the following limitations of our study. First, only a small number of patients were included. However, a high number of paired $\mathrm{EtCO}_{2}$ and $\mathrm{PaCO}_{2}$ could be analyzed. As the correlation was poor with very high limits of agreements, it is unlikely that increasing the number of patients would have significantly modified the results. Second, this study used a specific system to measure
$\mathrm{EtCO}_{2}$ and we cannot exclude that using another device could have yielded different results. Third, only one $\mathrm{EtCO}_{2}$ value was recorded at each time. Even if the quality of the corresponding capnogram was carefully checked, we cannot exclude that averaging the values of several respiratory cycles could have provided slightly different results. However, as airway resistance usually not varies between one breath and the following, this effect, if present, should be

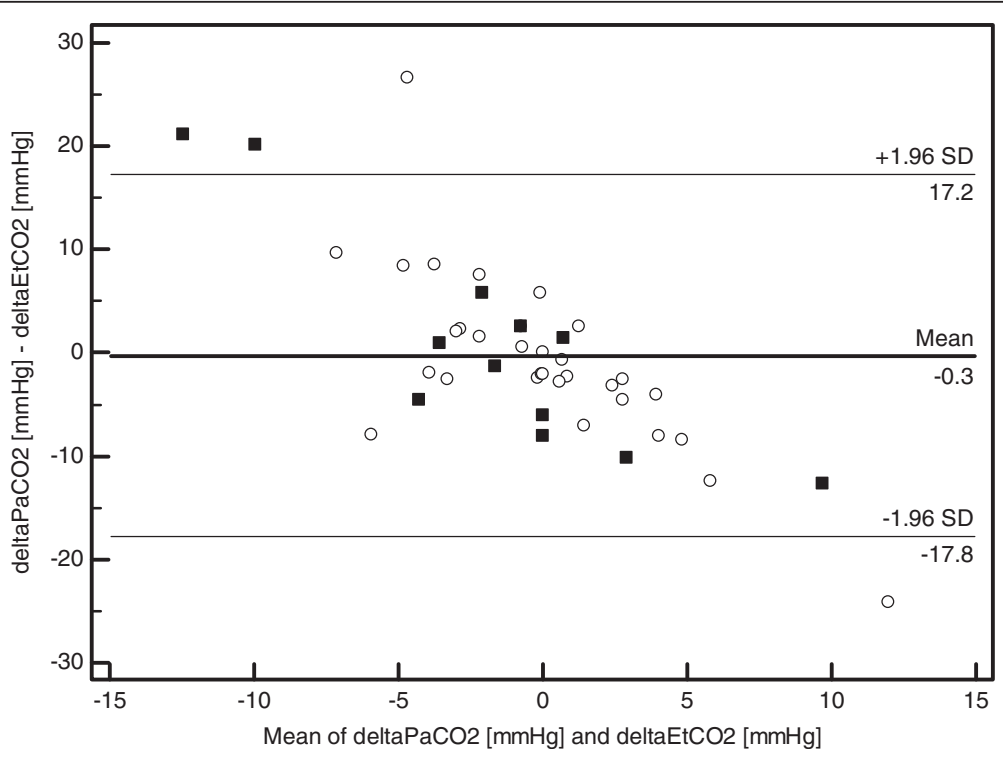

Figure 3 Bland-Altman plot of agreement between delta $\mathrm{PaCO}_{2}$ and delta $\mathrm{EtCO}_{2}$. Bland-Altman plot of agreement between delta PaCO and delta $\mathrm{EtCO}_{2}$. $\mathrm{PaCO}_{2}, \mathrm{CO}_{2}$ partial pressure in arterial blood; $\mathrm{EtCO}_{2}$, end-tidal $\mathrm{CO}_{2}$; circle markers, $\mathrm{COPD}$ patients values; square markers, non-COPD patients values; COPD, chronic obstructive pulmonary disease. The horizontal lines represent the bias and the upper and lower limits of agreement. 


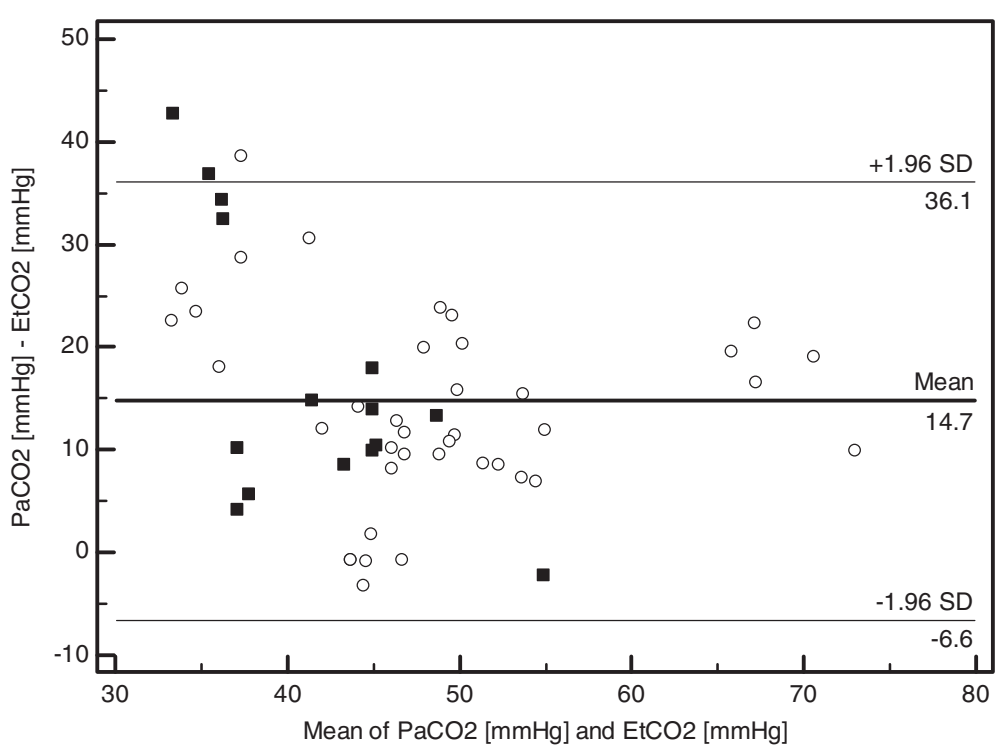

Figure 4 Bland-Altman plot of agreement between $\mathrm{PaCO}_{2}$ and $\mathrm{EtCO}_{2}$. Bland-Altman plot of agreement between $\mathrm{PaCO}_{2}$ and $\mathrm{EtCO}_{2}$. $\mathrm{PaCO}$, $\mathrm{CO}_{2}$ partial pressure in arterial blood; $\mathrm{EtCO}_{2}$, end-tidal $\mathrm{CO}_{2}$; circle markers, COPD patients values; square markers, non-COPD patients values; $\mathrm{COPD}$, chronic obstructive pulmonary disease. The horizontal lines represent the bias and the upper and lower limits of agreement.

minor. Fourth, using another patient-ventilator interface or other ventilators, e.g., ICU ventilators equipped with inspiro-expiratory circuits, might also lead to different results. Fifth, during the active and passive complete expiration maneuvers, some patients could potentially not have emptied their lungs enough to reach the residual volume because of maneuver intolerance or because they had to expire through the breathing circuit against the set PEEP.
Thus, expired $\mathrm{CO}_{2}$ values might not truly reflect expired $\mathrm{CO}_{2}$ at residual lung volume. Finally, we cannot exclude that different results could have been found if we had measured $\mathrm{EtCO}_{2}$ after stopping NIV treatment. However, as, in clinical practice, it can be difficult or even dangerous to interrupt NIV treatment in patients suffering from acute respiratory failure, we did not test this alternative approach.

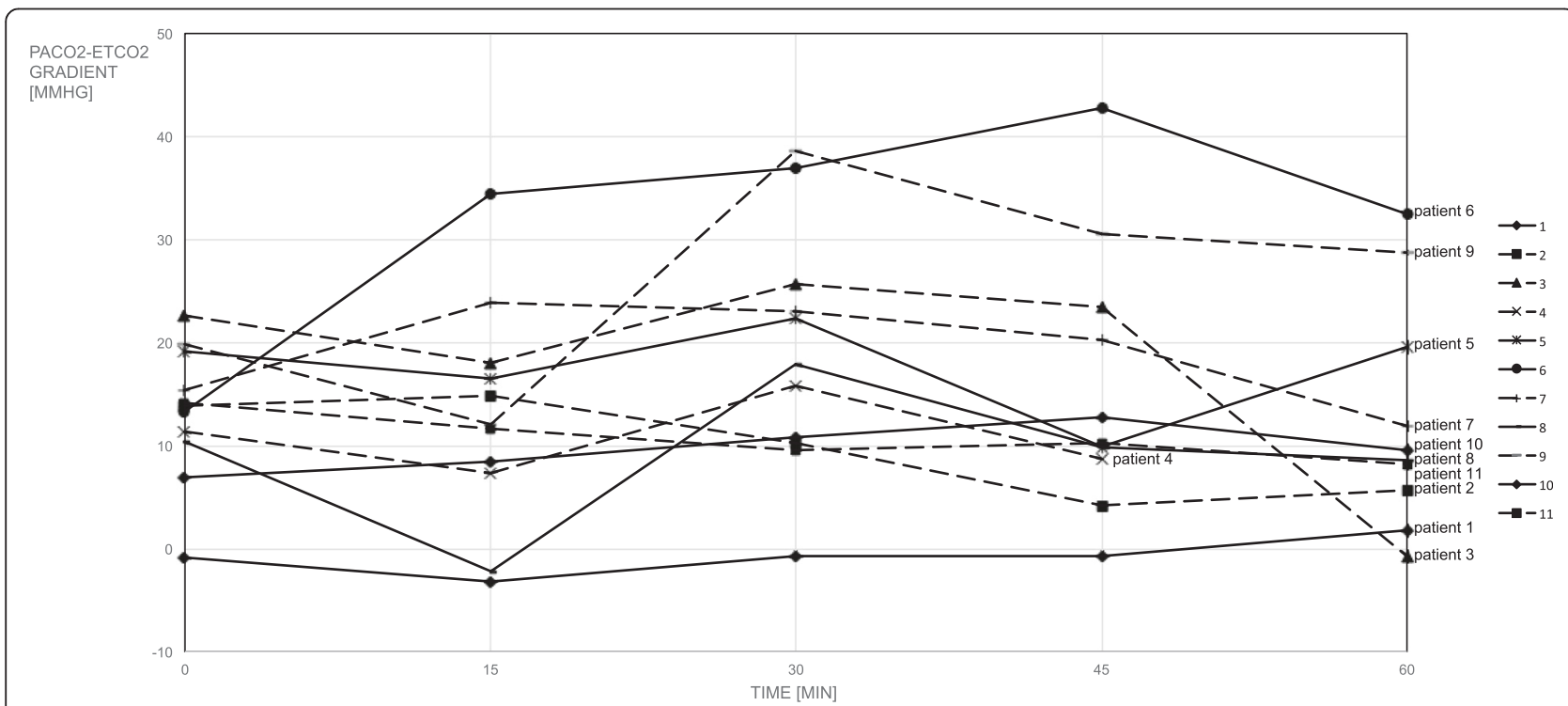

Figure 5 Evolution over time of $\mathrm{PaCO}_{2}-\mathrm{EtCO}_{2}$ gradient for all the patients. This figure shows the evolution over time of $\mathrm{PaCO}_{2}-\mathrm{EtCO}_{2}$ gradient for all the patients. $\mathrm{PaCO}_{2}, \mathrm{CO}_{2}$ partial pressure in arterial blood; $\mathrm{EtCO}_{2}$, end-tidal $\mathrm{CO}_{2}$. Patient numbers $1,3,4,5,7,9,10$, and 11 are COPD patients. 

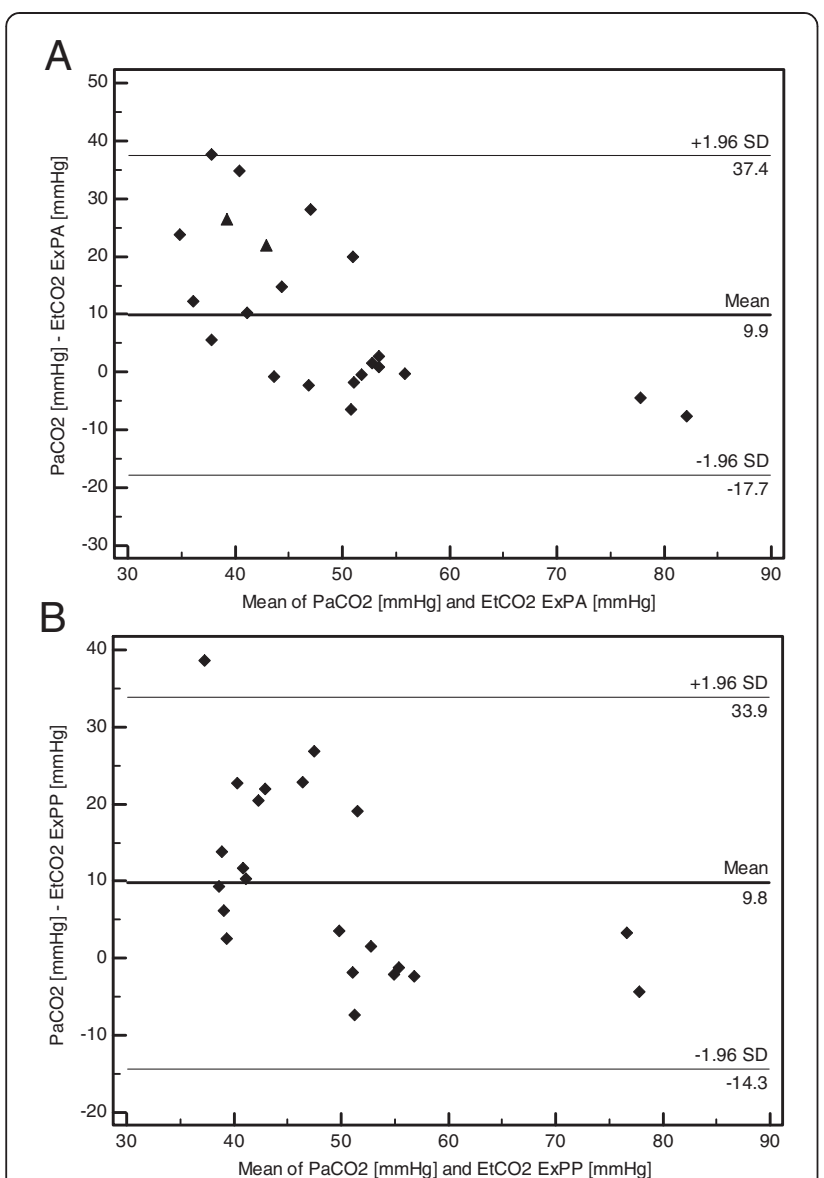

Figure 6 Bland-Altman plot of agreement between $\mathrm{PaCO}_{2}$ and expired $\mathrm{CO}_{2}$ after active and passive maximal expiration maneuvers. A Bland-Altman plot of agreement between $\mathrm{PaCO}_{2}$ and expired $\mathrm{CO}_{2}$ after active maximal expiration maneuver (ExPA). B Bland-Altman plot of agreement between $\mathrm{PaCO}_{2}$ and Expired $\mathrm{CO}_{2}$ after passive maximal expiration maneuver (ExPP). $\mathrm{PaCO}_{2}, \mathrm{CO}_{2}$ partial pressure in arterial blood. In both figures, the horizontal lines represent the bias and the upper and lower limits of agreement.

$\mathrm{EtCO}_{2}$ has been efficiently used for decades in intubated anesthetized patients [7] to monitor $\mathrm{PaCO}_{2}$ and ventilation, although many limitations have been recognized, particularly for patients suffering from chronic respiratory diseases (increased VD/VT ratio [8], airflow limitation) or hemodynamic instability leading to ventilation-perfusion mismatches [7,9]. Nasal $\mathrm{EtCO}_{2}$ has been successfully used to monitor normocapnic patients with almost healthy lungs undergoing regional anesthesia or recovering from general anesthesia [10]. In line with the results of the present study, two studies performed in spontaneously breathing patients suffering from acute respiratory failure found poor agreement between $\mathrm{EtCO}_{2}$ and $\mathrm{PaCO}_{2}$ values [11,12]. Oppositely, in more stable and tracheotomized patients, $\mathrm{EtCO}_{2}$ values were closer to $\mathrm{PaCO}_{2}$ values [13].
In contrast to our results (see Figure 4), in this last study [13], the agreement between $\mathrm{EtCO}_{2}$ and $\mathrm{PaCO}_{2}$ was better in non-COPD patients than in those suffering from COPD. This last point suggests that during NIV, physiopathological reasons probably do not explain by themselves the poor performances of $\mathrm{EtCO}_{2}$ measurement. A possible explanation for the poor agreement we observed between $\mathrm{EtCO}_{2}$ and $\mathrm{PaCO}_{2}$ during NIV could be the presence of a high airflow and of significant and often variable leaks during NIV that may have caused sampled expiratory gas dilution.

To try to overcome the expected limitation of $\mathrm{EtCO}_{2}$ measurement to assess $\mathrm{PaCO}_{2}$ absolute values and based on the assumption that, in the absence of major haemodynamic instability and of bronchodilatator administration, $\mathrm{Pa}-{ }_{\mathrm{E}} \mathrm{CO}_{2}$, even if often unpredictable, might be sufficiently constant over an hour in a given patient to enable the tracking of $\mathrm{PaCO}_{2}$ evolution, we assessed the time evolution of $\mathrm{EtCO}_{2}$ and $\mathrm{PaCO}_{2}$. This approach clearly reduced the bias, but the wide limits of agreement preclude its clinical use. Of course, we cannot exclude that physiological reasons, as alveolar recruitment occurring during NIV, could have decreased the VD/VT ratio and contibutated to the poor performance of $\mathrm{EtCO}_{2}$ variations to assess $\mathrm{PaCO}_{2}$ variations during NIV. However in this situation, $\mathrm{EtCO}_{2}$ values would have been closer to $\mathrm{PaCO}_{2}$ values at the end of the 1-h NIV treatment, which was not the case.

To try to better assess $\mathrm{PaCO}_{2}$, we also attempted to sample gas closer to the alveolar compartment by measuring expiratory $\mathrm{CO}_{2}$ at the end of a 'complete' expiration (either active or passive) [14] but this approach was also disappointing. Again, this observation contrasts with a study on stable tracheostomized patients [13] and underlines that performing reliable complete expiration maneuvers in acutely ill patients is very difficult.

The present study suggests that other technologies should be considered to non-invasively assess $\mathrm{PaCO}_{2}$ and $\mathrm{PaCO}_{2}$ over time during NIV. Even if the reliability of using transcutaneous $\mathrm{CO}_{2}$ monitoring to assess $\mathrm{PaCO}_{2}$ in case of acute respiratory failure is still contoversial $[15,16]$, recent technological improvements in the transcutaneous $\mathrm{CO}_{2}$ monitoring technology suggest that this technique could be of interest to monitor $\mathrm{PaCO}_{2}$ during NIV. This hypothesis, however, should be formally explored prospectively.

\section{Conclusions}

When a naso-buccal sensor is used, major variations of $\mathrm{Pa}_{-}, \mathrm{CO}_{2}$ along time and poor limits of agreements between $\mathrm{EtCO}_{2}$ and $\mathrm{PaCO}_{2}$ preclude the use of $\mathrm{EtCO}_{2}$ measurement to predict $\mathrm{PaCO}_{2}$ or its variation over time during NIV delivered for acute hypercapnic respiratory failure. Adding complete expiration maneuvers, whether 
passive or active did not improve $\mathrm{PaCO}_{2}$ prediction using $\mathrm{EtCO}_{2}$ during NIV. The optimal approach to noninvasively monitor $\mathrm{PaCO}_{2}$ during NIV in patients with acute hypercapnic respiratory failure remains to be determined.

\section{Competing interests}

The authors declare that they have no competing interests.

\section{Authors' contributions}

LP participated in the design of the study, conducted the study, contributed to statistical analysis, and drafted the manuscript. DT participated in the design of the study, collected the data, and helped with the data analysis and presentation. PJ participated in the design of the study and extensively revised the manuscript. JPR participated in the design of the study, performed the statistical analysis, and extensively revised the manuscript. All authors read and approved the final manuscript.

\section{Acknowledgments}

The $\mathrm{EtCO}_{2}$ recording system and the dedicated nasal canulas were kindly provided free of charge by Oridion Medical Ltd., Jerusalem, Israël.

\section{Author details}

${ }^{1}$ Adult Intensive Care and Burn Unit, University Hospital of Lausanne, Lausanne, Switzerland. ${ }^{2}$ Cardio-Respiratory Physiotherapy Unit, University Hospital of Lausanne, Lausanne, Switzerland.

Received: 19 August 2014 Accepted: 30 December 2014

\section{Published online: 12 February 2015}

\section{References}

1. Nava S, Hill N. Non-invasive ventilation in acute respiratory failure. Lancet. 2009:374:250-9.

2. Ferrer M, Esquinas A, Arancibia F, Bauer T, Gonzalez G, Carrillo A, et al. Noninvasive ventilation during persistent weaning failure: a randomized controlled trial. Am J Respir Crit Care Med. 2003;168:70-6.

3. Keenan SP, Powers C, McCormack DG, Block G. Noninvasive positive-pressure ventilation for postextubation respiratory distress: a randomized controlled trial. JAMA. 2002;287:3238-44.

4. Esteban A, Frutos-Vivar F, Ferguson ND, Arabi Y, Apezteguia C, Gonzalez M, et al. Noninvasive positive-pressure ventilation for respiratory failure after extubation. N Engl J Med. 2004;350:2452-60.

5. Takki S, Aromaa U, Kauste A. The validity and usefulness of the end-tidal pCO 2 during anaesthesia. Ann Clin Res. 1972;4:278-84.

6. Whitesell R, Asiddao C, Gollman D, Jablonski J. Relationship between arterial and peak expired carbon dioxide pressure during anesthesia and factors influencing the difference. Anesth Analg. 1981;60:508-12.

7. Moon RE, Camporesi EM. Respiratory monitoring. In: Miller DR, editor. Miller's anesthesia. Volume 4th edition. 4th ed. New York: Churchil Livingtone; 1994. p. 1253-91.

8. Hoffman RA, Krieger BP, Kramer MR, Segel S, Bizousky F, Gazeroglu H, et al. End-tidal carbon dioxide in critically ill patients during changes in mechanical ventilation. Am Rev Respir Dis. 1989;140:1265-8.

9. Fletcher R, Jonson B, Cumming G, Brew J. The concept of deadspace with special reference to the single breath test for carbon dioxide. $\mathrm{Br} J$ Anaesth. 1981;53:77-88

10. Raheem MS, Wahba OM. A nasal catheter for the measurement of end-tidal carbon dioxide in spontaneously breathing patients: a preliminary evaluation. Anesth Analg. 2010;110:1039-42.

11. Jabre P, Jacob L, Auger H, Jaulin C, Monribot M, Aurore A, et al. Capnography monitoring in nonintubated patients with respiratory distress. Am J Emerg Med. 2009:27:1056-9.

12. Delerme S, Freund Y, Renault R, Devilliers C, Castro S, Chopin S, et al. Concordance between capnography and capnia in adults admitted for acute dyspnea in an ED. Am J Emerg Med. 2010;28:711-4.

13. Johnson DC, Batool S, Dalbec R. Transcutaneous carbon dioxide pressure monitoring in a specialized weaning unit. Respir Care. 2008;53:1042-7.
14. Takano Y, Sakamoto O, Kiyofuji C, Ito K. A comparison of the end-tidal CO2 measured by portable capnometer and the arterial PCO2 in spontaneously breathing patients. Respir Med. 2003;97:476-81.

15. Gancel PE, Roupie E, Guittet L, Laplume S, Terzi N. Accuracy of a transcutaneous carbon dioxide pressure monitoring device in emergency room patients with acute respiratory failure. Intensive Care Med. 2011;37:348-51.

16. Kelly AM, Klim S. Agreement between arterial and transcutaneous PCO2 in patients undergoing non-invasive ventilation. Respir Med. 2011;105:226-9.

\section{Submit your manuscript to a SpringerOpen ${ }^{\circ}$ journal and benefit from:}

- Convenient online submission

- Rigorous peer review

- Immediate publication on acceptance

- Open access: articles freely available online

- High visibility within the field

- Retaining the copyright to your article

Submit your next manuscript at $>$ springeropen.com 